\title{
THE IMPACT OF EMOTIONS IN IMMERSIVE JOURNALISM
}

\author{
Turo Uskali and Pasi Ikonen
}

One of the starting motivations for developing the very concept and practice of immersive journalism was concern about the audiences' general apathy toward news reporting. As Nonny de la Peña et al. $(2010,298)$ stated in their seminal paper, "An important role of immersive journalism could be to reinstitute the audience's emotional involvement in current events". As a documentarist, de la Peña was more familiar with "emotional literacy" than an average news reporter, for example (see Pantti 2010, 176).

Virtual reality (VR) experiences indeed trigger emotions more effectively than many traditional forms of media content, according to many scholars (Doyle et al. 2016; Sundar et al. 2017; Bailenson 2018; Schilowitz 2017; Evans 2019, 4.) Therefore, one of the core challenges of immersive journalism, even still in its infancy, is the potential to cause strong emotions, positive and negative, in its audience. Every novel communication form creates new concerns. Like any transformative technology, VR comes with significant risks.

This chapter draws from journalism studies, health sciences, and ethics. We first outline the contemporary emotional turn in journalism studies. Second, we summarize the results of studies of the effects of VR treatments and other health-related issues. Third, we focus on ethical questions in relation to immersive journalism, especially pondering the need for possible updates and fine-tuning for traditional journalism ethics. Finally, based on the aforementioned perspectives we draft some instructions and ethical guidelines for immersive journalism.

The study of emotions is nothing new. Scholars in psychology and sociology were among the pioneers, starting with William James in 1884 (Wahl-Jorgensen 2019, 4). According to the Oxford English Dictionary (2019), emotion is a strong mental or instinctive feeling "deriving from one's circumstances, mood, or relationships with others". In communication and business studies, marketing has led the way 
in studying emotions. According to Andrew McStay (2016, 4) "advertising and emotions have always professionally gone hand-in-hand".

Mervi Pantti $(2010,169)$, who was among the first scholars to examine the role of emotions in journalism, has argued that emotionality in journalism and academic research has typically been seen as lowering the basic standards of the craft. It has been perceived as linked more to entertainment, tabloid journalism, or sensationalism, than serious, fact-based narratives.

There have been several roadblocks to studying emotions in journalism, according to Karin Wahl-Jorgenson (2019, 29-30), especially the professional ideal of objectivity, which has been traditionally defined as "the polar opposite of emotion". She divides scholarship on journalism and emotion into three categories: 1) understanding how journalistic practices are shaped by emotion and emotional labor, 2) studying emotion in journalistic texts, and 3) studying audience emotional engagement with news (ibid., 30). She concludes that "despite the persistence of the ideal of objectivity, emotional storytelling is, in fact, central to the world-making powers of journalism" (ibid., 35).

Good stories, images, and videos have always captured emotions, and thus emotions have always been explicitly or implicitly present in many journalistic works, especially in longer forms of storytelling, nonfiction human interest stories, and TV documentaries. Crisis reporting has also traditionally offered many emotional experiences via photographs, films, and videos (Pantti 2010, 172-173.)

In a similar vein, Chris Peters (2011) has argued that news has always been emotional, but journalists have not been able to show their own emotions, even in times of distress. Furthermore, Peters has emphasized that one of the most significant changes with reference to emotions in journalism practice has been that the "diversity of emotional styles, the acceptability of involvement on behalf of the journalist, and attempts to involve the audience have become more explicit" (ibid., 299).

By focusing on the emotive influences of immersive journalism, this chapter relates to the growing body of research literature that is forming the newest turn in journalism studies: emotion (Pantti 2010; Peters 2011; Beckett \& Deuze 2016; Lindgren 2017, 127-144; Wahl-Jorgensen 2019; Nikunen 2019.) Moreover, the term "affective turn" is already in scholarly use (Lindgren 2017, 127; WahlJorgenson 2019, 30).

Charlie Beckett and Mark Deuze $(2016,1)$ have argued, for example, that "as journalism and society change, emotion is becoming a much more important dynamic in how news is produced and consumed". Interestingly, Beckett and Deuze have not referred directly to VR, potentially the most immersive and emotional new technology available for journalistic storytelling.

\section{The question of emotional manipulation}

This shift toward more emotive public communication and media culture could be explained by the rise of the internet and social media, which have enabled new emotional communication forms and habits (Peters 2011,301; Lindgren 2017, 128). 
In addition, mobile phones' real-time messaging in the 1990s, and especially the use of emoticons, i.e., emotion icons, has paved the way for the use of emotions in digital communication. Of course, for centuries love letters and other forms of emotional correspondence were a common private practice. In that sense there is nothing new but the magnitude, intensity, and real-time feedback of the messages.

José van Dijck et al. (2018) have used the term "platform society" to illustrate how online platforms and societal structures are already intertwined. They have also emphasized that the platform companies often bypass old organizations and regulations (ibid, 1). Interestingly, they have not mentioned how the platform companies have already heavily invested in immersive technologies, potentially the next phase of human communication systems (see also Chapter 8). According to Frank Biocca and Mark Levy $(1995,127)$, already in the early 1990s introductory VR books often described VR as "the next logical step in the history of communication".

Platform companies' powerful position has already led to some serious ethical discussions. For example, Facebook has been blamed particularly for massive-scale emotional tests (Kramer et al. 2014; Jouhki et al. 2016) and for being the main publishing platform of a form of digital advertising that has been called "fake news" (Silverman 2016; van Dijck et al. 2018, 49). Increasing awareness and critical public debates have created pressures, especially in the European Union, to combat misinformation and disinformation and to regulate the platform companies (Bakir \& McStay 2018, 155).

As David Hesmondhalgh (2019, xxi-xxii) has analyzed, there is a constant battle between the "doomed dinosaurs", traditional cultural industries including media organizations, and their "crucial frenemies", the IT industries. He writes that "it is increasingly obvious that the new world of digital networks has some extremely worrying aspects", such as in terms of surveillance.

In addition, according to McStay (2016, 1-3), "emotiveillance" has already been tested in reality, for example emotional surveillance by advertisers. In London in 2015, marketing company M\&C Saatchi produced an advert for a fictional coffee brand that changed according to people's facial reactions. It was presumably the first time that data about emotions was collected automatically for improving an advert's performance. This improvement was done by replacing elements that did not bring enough positive responses.

McStay $(2016,1)$ has also coined the "empathic media" concept, which refers to "technologies that track bodies and react to emotions and intentions". These "empathic media" technologies include, for example, facial coding, voice analytics, VR, augmented reality, and wearables. Based on these technologies, the users' emotions could be machine-readable, and this data could be used for influence and surveillance (Bakir \& McStay 2018, 155). McStay (ibid., 10) emphasizes that collecting and using intimate data raises legal and ethical questions, but he does not yet offer any answers for this "emotion-sensitive advertising".

According to Pantti (2010,178), in television journalism the most important question regarding emotion has been "How much emotion is too much?" This 
is also a valid concern for immersive journalism. As the development of immersive journalism is still only in its early stages and no mass audiences exist yet, it is important to start critical scholarly examination about the potential health issues and ethical implications of immersive technologies for journalism early enough.

\section{Virtual reality and health effects: positive and negative}

Physicians and psychotherapists have been in the forefront of adopting VR technologies in their work. According to VR treatments research literature, positive results have been published already for two decades. These range from VR exposure therapy for phobias (Emmelkamp et al., 2001; Bowman \& McMahan 2007; Parsons \& Rizzo 2008; Diemer et al. 2015) to VR treatment for reducing pain (Hoffman et al. 2000; Hoffman et al. 2004; Malloy \& Milling 2010), and, more recently, VR treatments for anxiety disorders (Opris et al. 2012).

According to the latest research, psychotherapists have usedVR exposure therapy successfully to treat fear of heights (Temming 2018), fear of flying, and fear of going to the dentist (Metz 2018). In medicine, VR has had an impact on reducing pain (Hooker 2019; Savran Kelly 2018; Bailenson 2018), detecting early risks of Altzheimer's (McKie 2018), neurological conditions (BBC.com 2018), and schizophrenia (Fidelman 2018). In addition,VR experiences have proved to be helpful in meditation practices (Garone 2018).

On the more negative side, VR experiences have also been proven to cause, for example, the loss of spatial awareness, dizziness and disorientation, seizures, nausea, eye soreness, trouble focusing, and motion or simulator sickness (Bailenson 2018; Fagan 2018). The term "cybersickness" has also been used in relation to immersive journalism (LaViola 2000; Hardee \& McMahan 2017).

According to Gary Hardee and Ryan McMahan (2017), there are three main theories for what causes motion sickness in VR experiences. First, the poison theory argues that during an immersive experience the body misinterprets the stimuli as a form of toxic substance. Second, the postural instability theory claims that prolonged postural instability results in motion sickness symptoms because humans are expected to maintain postural stability. Third, and perhaps the most believable of all, is the sensory conflict theory, which is based on an assumption that the body does not know how to handle mixed signals or inconsistencies in relation to motion and the body's orientation.

Psychologist and communication scholar Jeremy Bailenson, from the Virtual Human Interaction (VHI) Lab, which was founded in 2003 at Stanford University, has been one of the study pioneers of how VR experiences could lead to changes in perceptions of self and others. He has been focusing on experiments on VR since the turn of the millennium.

According to Jeremy Bailenson (2018), people's VR experiences indeed have an impact on them and have psychological effects. Of course, these effects could be both positive and negative.VR experiences could encourage empathic understanding, often understood as "perspective-taking" or "walking in another's shoes". When 
head-mounted display users immerse themselves in closed VR experiences, their attention drifts away from their own bodies. Bailenson also mentions that this has been useful especially for pain reduction. On the negative side, he reminds that watching and listening to VR experiences could also cause "compassion fatigue" that can trigger anxiety, nightmares, and even burnout.

In Finland, we conducted our own empirical user tests on emotional reactions to immersive journalism experiences. The first pilot was with journalism students $(\mathrm{n}=20)$. Additional focus group interviews with journalism students $(\mathrm{n}=27)$ and VR journalism professionals $(n=4)$ followed. The tests, even at this small scale, provided a clear picture of ethical challenges as well as VR journalism's potential benefits and pitfalls. Based on our own tests, including nine different minidocumentaries or immersive experiences with journalism students, the main result was that the same experiences could generate many different reactions, depending on the person and their background. Therefore, we can claim that immersive journalism stories are far more complicated, nuanced, and provide a more subjective experience than previously thought (Uskali et al. 2019).

Based on our findings, we can argue that negative motion sickness effects do exist, but they vary from person to person. Regarding immersive journalism, one important aim should always be to avoid any motion sickness effects. The easiest way to do this is just to remember not to move the cameras (see also Hardee \& McMahan 2017). According to our research, surprisingly many mini-documentaries in 2018 still included segments that used 360-degree cameras in motion.

In conclusion, we argue that immersive journalism, when using the VR storytelling methods, operates in a sensitive emotional area that also needs serious consideration of ethics.

\section{Ethical implications: a need for updates and fine-tuning}

Crisis reporting has traditionally regularly offered journalism ethics cases that are also related to health questions, especially in terms of journalists' safety. Unpredictable and hazardous work environments have caused the deaths of hundreds of journalists, not only in war zones, conflict areas, or catastrophe situations, but also when investigating sensitive issues such as corruption and other crimes (Carlsson \& Pöyhtäri 2017). Of course, every death of a journalist is one too many, and signals either too much risk taking or too little protection from the newsrooms and governments.

Stephen Ward (2018) has defined journalism ethics as the "responsible use of the freedom to publish; it is the study and application of the norms that should guide responsible, public journalism". Ethical considerations, especially by photojournalists, have often concentrated on the use of violent, cruel, and pornographic materials. However, other kinds of ethical issues also exist, such as questions of authenticity, truthfulness, verification, and privacy. These are also all valid concerns for immersive journalism.

Recently, more brutal and graphic images have been shared on social media platforms than have ever been broadcast on news media. But journalism ethics still 
matter, and all decisions should be based on ethical considerations and professional codes. Journalism ethical standards offer a valuable basis for immersive journalism practices, but, we, to some degree, agree with Ward (2018) that there is indeed a need for some updates and fine-tuning. Ward has emphasized the need to even disrupt traditional journalism ethics due to "the digital media revolution". He argues that "journalism ethics should become a new, more complex, and conceptually deeper, global ethics for responsible communication" (Ibid.).

In a similar vein, Kathleen Bartzen Culver (2015) has summarized this need for ethical updates in immersive journalism:

In some cases, traditional ethics contested over decades help inform our judgments. But in others, the very immersion itself prompts questions we have not yet tackled in journalism.

Culver 2015

Philosophers Michael Madary and Thomas Metzinger (2016, 5) have already warned about the manipulative power of VR technologies (see also Chapter 7.):

The comprehensive character of VR plus the potential for the global control of experiential content introduces opportunities for new and especially powerful forms of both mental and behavioral manipulation, especially when commercial, political, religious, or governmental interests are behind the creation and maintenance of the virtual worlds.

Metzinger 2016, 5, 3

As a senior editor at Associated Press, Tom Kent (2015) has predicted: "It's only a matter of time until VR simulation looks more and more like the actual event". Therefore, Kent has emphasized the need for transparency and also special VR ethics statements. Furthermore, he has argued that:

Clearly, journalism's job is to bring human drama alive for distant audiences. But creating empathy is a goal beyond just telling a story. If the ultimate aim is to create emotion, a journalist could be tempted to omit balancing or inconvenient information that could interfere with the desired emotional effect.

Kent 2015

Kent has also started a crowdsourcing project to create a VR journalism code of ethics via the Online Journalism Association. At the time of writing in summer 2019 it only consisted of Kent's introduction, in which Kent separates two types of VR journalism stories: 1) capturing the reality, or 2) aimed at more than capturing reality, for example, re-creating an actual news event. He writes: "when re-creating a news event that wasn't captured originally by VR cameras, the ethical issues are even greater". He also wonders whetherVR stories including violence could cause post-traumatic stress in the viewer (Kent 2019). 
Dan Robitzski (2017) has argued that many publications' first experiments with VR raise new ethical considerations, "not only about how these stories are produced, but also about the ways in which audiences experience and remember them". In the first VR stories, audiences were transported to "less innocuous situations", such as a war zone or a prison cell in solitary confinement.

Photojournalism ethics, which are based on the notion that the images should not be altered, are solid ground for immersive journalism. Another ethical question is privacy. As the video captures everything in 360-degrees, it can be challenging to hide anything or anybody; everything is on the scene, including tripods and the journalists. One can try to hide or edit content afterwards in post-production, but it raises the question of authenticity. According to Kathleen Bartzen Culver (2015), "privacy is clearly one of the largest ethical considerations for journalists with immersives, especially 360-degree video". She also reminds us that:

Virtual reality that relies on video capture, for instance, poses the problem of incidental capture. Imagine an immersive experience designed to transport users to a Liberian hospital treating patients with Ebola.

Culver 2015

There are constant ethical ponderings in newsrooms concerning what to show to the audience. However, in 360-degree videos and especially 360-degree real-time streams, it is harder to make any ethical decisions with that pace. In general, people are not yet aware of 360-degree cameras and their capabilities, compared with 2D devices. Also, 360-degree microphones may capture incidentally conversations or comments that are not meant for the public. In this way, the journalist should behave ethically and consider informing people at the scenes being recorded.

\section{Protecting children: What is the right age?}

The use of VR by children has created further concern (see also Paura 2018). According to Jaron Lanier $(2018,118)$, “there's a consensus in theVR research community that kids shouldn't get into VR before about age six, and some researchers recommend waiting until eight or nine". The health and safety guide for the Oculus Rift and Touch headsets (Oculus 2019) forbids the use of the device by children under 13 years old. The guide explains that the headset is not the proper size for children, and that younger children are in a critical period in their visual development. Children's susceptibility toward acquiring false memories is another point of concern (Bailenson 2018, 992).

In TV news, for example, warnings by the news anchors of upcoming disturbing material have often preceded the insert but without any age recommendations. So far, The Guardian has been one of the few news media organizations that has provided special instructions and age recommendations for immersive journalism users. It has also informed its immersive journalism audience that if they feel sick or 
uncomfortable, the head-mounted displays should be taken off. Furthermore, they have been advised to sit down and avoid placing any hot drinks nearby (Panetta 2016). At the beginning of an immersive experience, such as in 6x9: Solitary confinement, a prison story, there is a warning:

Before you watch further you should be aware that this virtual experience has disturbing material and could provoke an emotional reaction. You should take this and your comfort level into consideration before you choose to continue. You must be at least 18 years old to participate in this virtual experience.

6×9: Solitary confinement - VR experience 2016

Another ethical issue, emphasized first by Ana Luisa Sánchez Laws (2019), is the use of children as informants in distressing news environments. Among the very first examples of immersive journalism were mini-documentaries, such as The Displaced (2015) and Clouds Over Sidra (2015), in which refugee children were the central characters of the stories (see also Yemen's Skies of Terror 2018). According to Sánchez Laws (ibid., 1), "the sensitivity required when presenting distressful events is even more important when working with minors as the subjects of these events". Of course, permission from the parents or other custodians should always be asked if underage persons are to be used as story subjects. This is in line with general journalism ethics.

\section{Conclusions}

It is easy to argue that immersive journalism is indeed a powerful new medium, which could have both positive and negative effects for its users. As feelings and emotions have entered research in journalism studies, immersive journalism represents a new and important study field that needs international collaboration and networks. Finally, we can perhaps even start talking about emotive immersive journalism, as emotions play an essential role in the closed virtual experiences and story narratives.

Even if research on the effects of immersive journalism is still scarce, and the user base is low, we can already argue, based on results from health sciences, that there is a need for health instructions and ethical fine-tuning in terms of immersive experiences.

Perhaps most important of all, there should be minimum ages set for immersive journalism. What the lowest age should be for immersive journalism experiences is still debatable. Motion picture and game content rating systems could also offer some guidance for immersive experiences. If there are any doubts that the content may cause psychological harm for its users, special warnings and age restrictions should be set. Of course, another question is how to control that these warnings are obeyed.

Immersive journalists should not only be aware of their own work ethics in the matter of emotive immersive storytelling but also be critically cautious toward 
possibly advanced and sophisticated manipulation and disinformation operations in the immersive journalism form. In ethics, special attention should be paid to the questions of suitable content and its authenticity.

\section{References}

Bailenson, Jeremy. 2018. Experience on Demand: What Virtual Reality Is, How It Works, and What It Can Do. 1st ed. New York: W.W. Norton \& Company.

Bakir,Vian \& Andrew McStay. 2017. "Fake News and the Economy of Emotions: Problems, Causes, Solutions.” Digital Journalism 6(2), July: 154-175.

BBC.com. 2018. "Virtual reality therapy opens new horizons for neurological conditions." BBC.com. 28 July. www.bbc.com/news/av/uk-scotland-44987550/virtual-reality-therapyopens-new-horizons-for-neurological-conditions [Accessed 23 February 2019].

Beckett, Charlie \& Mark Deuze. 2016. "On the role of emotion in the future of journalism." Social Media Society 2(3), September: 1-6.

Biocca, Frank \& Mark R. Levy. 1995. "Communication applications of virtual reality." In: F. Biocca \& M.R. Levy (eds.), LEA's Communication Series: Communication in the Age of Virtual Reality. Hillsdale, NNJ: Lawrence Erlbaum, pp. 127-157.

Bowman, Doug A. \& Ryan P. McMahan. 2007. "Virtual reality: How much immersion is enough?” IEEE Computer 40(7), July: 36-43. doi:10.1109/MC.2007.257

Carlsson, Ulla \& Reeta Pöyhtäri (eds). 2017. The Assault on Journalism: Building Knowledge to Protect Freedom of Expression. Gothenburg, Sweden: Nordicom.

Culver, Kathleen B. 2015. "Immersive approaches pose new questions." 11 February. Wisconsin: Center for Journalism Ethics, University of Wisconsin-Madison. https:// ethics.journalism.wisc.edu/category/virtual-reality/ [Accessed 9 March 2019].

de la Peña, Nonny, Peggy Weil, Joan Llobera, Elias Giannopoulos, Ausias Pomés, Bernhard Spanlang, Doron Friedman, Maria V. Sanchez-Vives, \& Mel Slater. 2010. "Immersive journalism: Immersive virtual reality for the first-person experience of news." Presence 9(4), August: 291-301.

Diemer, Julia, Georg W.Alpers, Henrik M. Peperkorn, Youssef Shiban, \& Andreas Mühlberger. 2015. "The impact of perception and presence on emotional reactions: A review of research in virtual reality." Frontiers in Psychology 6(26), January.

Doyle, Patrick, Mitch Gelman, \& Sam Gill. 2016. Viewing the Future? Virtual Reality in Journalism. Knight Foundation. https://knightfoundation.org/reports/vrjournalism [Accessed 22 February 2019].

Emmelkamp, Paul M., Mary Bruynzeel, Leonie Drost, \& C.A.G. van der Mast. 2001. "Virtual reality treatment in acrophobia: A comparison with exposure in vivo." CyberPsychology $\mathcal{E}$ Behavior 4(3), June: 335-339.

Evans, Leighton. 2019. The Re-Emergence of Virtual Reality. 1st ed. London: Routledge.

Fagan, Kaylee. 2018. "Here's what happens to your body when you've been in virtual reality too long." Business Insider. www.businessinsider.com/virtual-reality-vr-sideeffects-2018-3?r=US\&IR=T [Accessed 4 March 2019].

Fidelman, Charlie. 2018. "People with schizophrenia learn to fight their demons with virtual reality." MontrealGazette.com. https://montrealgazette.com/health/montreal-researcherhas-patients-fighting-their-demons-with-virtual-reality [Accessed 7 August 2019].

Garone, Sarah. 2018. "Why virtual reality is a game-changer for my meditation practice." Brit + Co, 15 August. www.brit.co/virtual-reality-meditation/ [Accessed 23 February 2019].

Hardee, Gary M. \& Ryan P. McMahan. 2017. "FIJI: A framework for the immersionjournalism intersection.” Frontiers in ICT 4(21), July. 
Hesmondhalgh, David. 2019. The Cultural Industries. 4th ed. London: SAGE.

Hoffman, Hunter G., David R. Patterson, \& Gretchen J. Carrougher. 2000. "Use of virtual reality for adjunctive treatment of adult burn pain during physical therapy: A controlled study." The Clinical Journal of Pain 16(3), September: 244-250.

Hoffman, Hunter G., Todd L. Richards, Barbara Coda, Aric R. Bills, David Blough, Anne L. Richards, \& Sam R. Sharar. 2004. "Modulation of thermal pain-related brain activity with virtual reality: Evidence from fMRI." Neuroreport 15(8), June: 1245-1248.

Hooker, Lucy. 2019. "How virtual reality can help you manage pain." BBC News, 23 January. www.bbc.com/news/av/business-46964729/how-virtual-reality-can-helpyou-manage-pain [Accessed 6 September 2019].

Jouhki, Jukka, Epp Lauk, Maija Penttinen, Niina Sormanen, \& Turo Uskali. 2016. "Facebook's emotional contagion experiment as a challenge to research ethics." Media and Communication 4(4), October: 75-85.

Kent, Tom. 2015. "An ethical reality check for virtual reality journalism.” Medium.com, 31 August. https://medium.com/@tjrkent/an-ethical-reality-check-for-virtual-realityjournalism-8e5230673507 [Accessed 15 March 2020].

Kent, Tom. 2019. "Virtual reality journalism." Online News Association. https://ethics. journalists.org/topics/virtual-reality-journalism-2/ [Accessed 27 September 2019].

Kramer,Adam D.I., Jamie E. Guillory, \& Jeffrey.T. Hancock. 2014. “Experimental evidence of massive-scale emotional contagion through social networks." In: Proceedings of the National Academy of Sciences of the United States of America 111(24), June: 8788-8790.

Lanier, Jaron. 2018. Dawn of the New Everything: A Journey Through Virtual Reality. London: Bodley Head.

LaViola, Joseph J. 2000. "A discussion of cybersickness in virtual environments." SIGCHI Bulletin 32(1), January: 47-56. doi:10.1145/333329.333344

Lindgren, Simon. 2017. Digital Media \& Society. London: SAGE.

Madary, Michael \& Thomas K.Metzinger. 2016. "Real virtuality: A code of ethical conduct: recommendations for good scientific practice and the consumers of VR-technology." Frontiers in Robotics and AI 3(3), February: 1-23.

Malloy, Kevin M. \& Leonard S. Milling. 2010. "The effectiveness of virtual reality distraction for pain reduction: A systematic review." Clinical Psychology Review 30(8), December: 1011-1018.

McKie, Robin. 2018. "Virtual reality to help detect early risk of Alzheimer's: Navigation skills tested through headsets may identify patients far earlier." The Guardian, 16 December. www.theguardian.com/society/2018/dec/16/alzheimers-dementia-curevirtual-reality-navigation-skills [Accessed 9 March 2019].

McStay, Andrew. 2016. "Empathic media and advertising: Industry, policy, legal and citizen perspectives (the case for intimacy)." Big Data \& Society 3(2), November: 1-11.

Metz, Rachel. 2018. "How VR is helping flyers and dental patients calm down." CNN. com, 10 December. https://edition.cnn.com/2018/12/10/tech/vr-dentist/index.html [Accessed 23 February 2019].

Nikunen, Kaarina. 2019. Media Solidarities: Emotions, Power and Justice in the Digital Age. London: SAGE.

Opriş, David, Sebastian Pintea, Azucena García-Palacios, Cristina Botella, Ştefan Szamosközi, \& Daniel David. 2012."Virtual reality exposure therapy in anxiety disorders: A quantitative meta-analysis." Depression and Anxiety 29(2), February: 85-93.

Oxford English Dictionary. 2019. www.oed.com/view/Entry/61249?.rskey=ed1fLA\&result=1 \&isAdvanced=false\#eid [Accessed 6 September 2019]. 
Panetta, Francesca. 2016. “6x9: A virtual reality experience of solitary confinement - FAQs.” The Guardian, 27 April. www.theguardian.com/world/2016/apr/27/6x9-vr-virtualreality-experience-solitary-confinement-faqs-explainer [Accessed 10 March 2019].

Pantti, Mervi. 2010."The value of emotion: An examination of television journalists' notions on emotionality." European Journal of Communication 25(2), June: 168-181.

Parsons, Thomas D. \& Albert A. Rizzo. 2008. "Affective outcomes of virtual reality exposure therapy for anxiety and specific phobias: A meta-analysis." Journal of Behavior Therapy and Experimental Psychiatry 39(3), October: 250-261.

Paura, Angelo. 2018. “The ethical challenges of immersive journalism.” Mediashift.org, February. http://mediashift.org/2018/02/the-ethical-challenges-of-immersive-journalism/ [Accessed 9 March 2019].

Peters, Chris. 2011. "Emotion aside or emotional side? Crafting an "experience of involvement' in the news." Journalism 12(3), April: 297-316.

Robitzski, Dan. 2017. "Virtual reality and journalistic ethics: Where are the lines?" Undark.org, 27 September. https://undark.org/article/virtual-reality-and-journalisticethics-where-are-the-lines/ [Accessed 9 March 2019].

Sánchez Laws, Ana Luisa. 2019. Conceptualizing Immersive Journalism. New York: Routledge.

Savran Kelly, J. 2018. "Relieving real pain in a virtual world." Cornell Chronicle. https://news. cornell.edu/stories/2018/04/relieving-real-pain-virtual-world [Accessed 30 April 2019].

Schilowitz,Ted. 2017. “Foreword.” In: John Bucher (ed.), Storytelling for Virtual Reality: Methods and Principles for Crafting Immersive Narratives. New York: Routledge, pp. ix-xi.

Silverman, Craig. 2016."This analysis shows how fake election news stories outperformed real news on Facebook." BuzzFeed News. www.buzzfeednews.com/article/craigsilverman/ viral-fake-election-news-outperformed-real-news-on-facebook [Accessed 16 November 2019].

Sundar, S. Shyam, Jin Kang, \& Danielle Oprean. 2017. "Being there in the midst of the story: How immersive journalism affects our perceptions and cognitions." Cyberpsychology, Behavior, and Social Networking 20(11), November: 672-682.

Temming, Maria. 2018. "Are you scared of heights? Virtual reality could help. In a therapy app, an avatar coaches people through sky-high situations." Sciencenewsforstudents.org. www.sciencenewsforstudents.org/article/are-you-scared-heights-virtual-reality-couldhelp [Accessed 14 August 2019].

Uskali, Turo, Esa Sirkkunen, Chelsea Kelling, Pasi Ikonen, \& Heli Väätäjä. 2019. "Testing immersive journalism experiences: Emotions and ethics." Paper presented at The Future of Journalism conference, Cardiff University, United Kingdom, 12 September.

van Dijck, José, Thomas Poell, \& Martijn De Waal. 2018. The Platform Society: Public Values in a Connective World. Oxford: Oxford University Press.

Wahl-Jorgensen, Karin. 2019. Emotions, Media and Politics. Hoboken, NJ: John Wiley \& Sons. Ward, Stephen J.A. 2018. Disrupting Journalism Ethics. London: Routledge. 